\title{
Institutional Hurdles to Student Humanitarian Groups: Lessons Learned from a Failed Project
}

\author{
Nathan Suhr \\ Graduate Student, Dept. of Civil Engineering \\ University of Idaho \\ Suhr7471@vandals.uidaho.edu
}

Riannon Heighes

Graduate Student, Dept. of Civil Engineering

University of Idaho

Heig0909@vandals.uidaho.edu

Rachel Hill

Graduate Student, Dept. of Civil Engineering

University of Idaho

Mcki8907@vandals.uidaho.edu

Kelby Sommers

Undergraduate Student, Civil Engineering

University of Idaho

Somm9743@vandals.uidaho.edu

\author{
Timothy Griswold \\ Undergraduate Student, Dept. of Chemical \\ Engineering \\ University of Idaho \\ Gris1509@vandals.uidaho.edu
}

\author{
Nathanael Hill \\ Undergraduate Student, General Studies \\ University of Idaho \\ Nate.1.hilll@gmail.com \\ Will Parker \\ Undergraduate Student, Dept. of Electrical and \\ Computer Engineering \\ University of Idaho \\ Park2681@vandals.uidaho.edu
}

Josh Suhr

External Team Member, EWB-UI

Jsuhr@kw.com

\author{
Fritz Fiedler P.E., PhD \\ Associate Professor, Dept. of Civil Engineering \\ University of Idaho \\ Fritz@uidaho.edu
}

\begin{abstract}
This paper examines the authors' experience with a small scale, community level development project and the challenges of working with a network of institutions. Smallscale development projects are supported by a network of institutions that are essential to project success but create an inherent level of complication that may be daunting to student-based humanitarian organizations. Through a thorough examination of this institutional system, its complexity, and mechanisms which can lead to a project failure, this paper contributes to the knowledge base available to the development community. First presented is the background and development of a University of Idaho Student Chapter of Engineers Without Borders chapter and their initial project in Bolivia, which ultimately failed. Our discussion will focus primarily on the interactions between the chapter and the primary institutions that we worked with including the University of Idaho, Engineers Without Borders USA, and Engineers in Action Bolivia. This is followed by an analysis of these interactions, the hurdles that arose within each institution, and recommendations for addressing such challenges. By examining these institutional hurdles, our goal is to provide other organizations with information useful to navigate the complex environment of community development work.
\end{abstract}




\section{INTRODUCTION}

The past decade and a half has represented a period of incredible growth in university based humanitarian projects and programs for engineers. This paper focuses on the experience of an Engineers Without Borders (EWB) student chapter as a case study, but humanitarian engineering programs independent of EWB have also formed in many colleges and universities across the country. These include programs such as the D-Lab at $\mathrm{MIT}^{1}$, humanitarian engineering minor at Colorado School of Mines ${ }^{2}$, HES at The Ohio State University ${ }^{3}$, ETHOS at the University of Dayton $^{4}$, and the DHE at Dartmouth ${ }^{5}$ among others. There have been many reasons cited to explain the dramatic increase in the number of programs such as these, including the inability of the current system to produce engineers who are also global citizens ${ }^{6}$ and the engagement of women and underrepresented minorities in the STEM fields ${ }^{7}$. Whatever the reason for this growth it is clear that the model of extended-length (multiple-year), small-scale (community level) humanitarian projects has grown to have a significant impacts on both the engineering community of the $21^{\text {st }}$ century and the communities that they serve.

Fundamental to engineering design is the redesign or improvement of the original product or process. Inherent to this process is the need to examine and learn from failures. Without examining unsuccessful projects it is difficult or impossible to conceive of meaningful improvements. The concept of redesign typically applies to the "hard" sciences, such as making improvements to the engineering design and construction process, but can be extended to aspects of operations for development organizations.

As discussed in the book Engineering for Sustainable Human Development ${ }^{8}$ there is a significant amount of criticism in literature specifically focused on small-scale development projects such as the type commonly implemented by EWB groups, due in part to the perceived high rates of failure of these types of projects. This has led to a rise in the creation of websites such as, Admitting Failure ${ }^{9}$, with pages for both US and Canadian failures, and Fail Forward ${ }^{10}$, where accounts of failed humanitarian projects are disseminated in order to provide an important record from which other teams may learn. While the trend of failure reporting is increasing in the last five years it is still more common to only report the successes. This unfortunate tendency removes a great opportunity for learning, stifling the process of learning from failure that is so critical to the engineering process.

Examining reported failures reveals some patterns. In the paper Learning from Failure, Mazzurco and Jesiek ${ }^{11}$ examine eight cases from various sources. The authors break project failure into two main categories: 1) failure to learn and 2) failure to apply knowledge. The authors sub-divide the "failure to learn" category into 1a) failure to assess needs, 1b) failure to understand the culture, and 1c) failure to assess assets. These modes of failure, while real and accurate, do not fully represent the spectrum of failure modes. After performing a literature review and examining the cases presented in the above sources, it is apparent that institutional failure, i.e. failure resulting from problems arising in the various institutions that student groups must work with (universities, humanitarian organizations, NGOs, and local governments), is not well documented. Development groups, especially student groups, are surrounded by a web of entities that they are responsible to in one form or another. In order to demonstrate the complicated nature of these relationships the authors have developed a graphic to visually demonstrate the relationships between the group, supporting organizations and community. This graphic is presented in the Background and History section below as Figure 1. This figure is not designed to be a comprehensive list but rather convey the complexity of relationships facing an 
organization preparing to undertake this type of work. These institutions aim to facilitate student service projects in various ways, but may also introduce barriers to project success. As shown in the timeline presented in Figure 2, also presented in the Background and History section some of the institutional failures can result in extended periods of inaction. This can be very difficult for an organization to overcome, especially a student organization where individual student involvement is often three years or less.

This paper describes the authors' experience with the Engineers Without Borders Student Chapter at the University of Idaho (EWB-UI) to examine the institutional hurdles of small-scale humanitarian work and to offer suggestions and lessons learned that may help other groups navigate the institutional landscape. We first provide an essentially chronological overview of the history of our EWB-UI group, from formation, through project adoption and finally (attempted) project implementation, with emphasis on institutional interactions. After the background is presented, we then examine some of the specific difficulties encountered and provide lessons learned and recommendations where possible. The goals are to contribute to the body of knowledge about project failure from a perspective not currently represented in the literature, initiate a dialog about the institutional hurdles facing student humanitarian groups, and to provide information that can be useful to groups whether they are newly formed or have been operating for years.

\section{BACKGROUND AND HISTORY}

The creation and evolution of EWB-UI has been tumultuous with setbacks occurring with all organizational partners and at many stages of the program process. These setbacks culminated with project termination. This section will present the history in chronological order so that the interdependent and complex nature of the relationships necessary for this type of development work can be examined. Taking an introspective look at these difficulties can provide organizations of all sizes information that can be used to prevent setbacks such as the ones experienced by EWB-UI. Figure 1 below shows a diagram of the majority of stakeholders that will be discussed in this section and their relationships to each other. In this diagram EWB-UI is the Idaho group responsible for the project. EWB-USA is the national branch of Engineers Without Borders and EIA is the in country NGO helping with logistics and communication. 


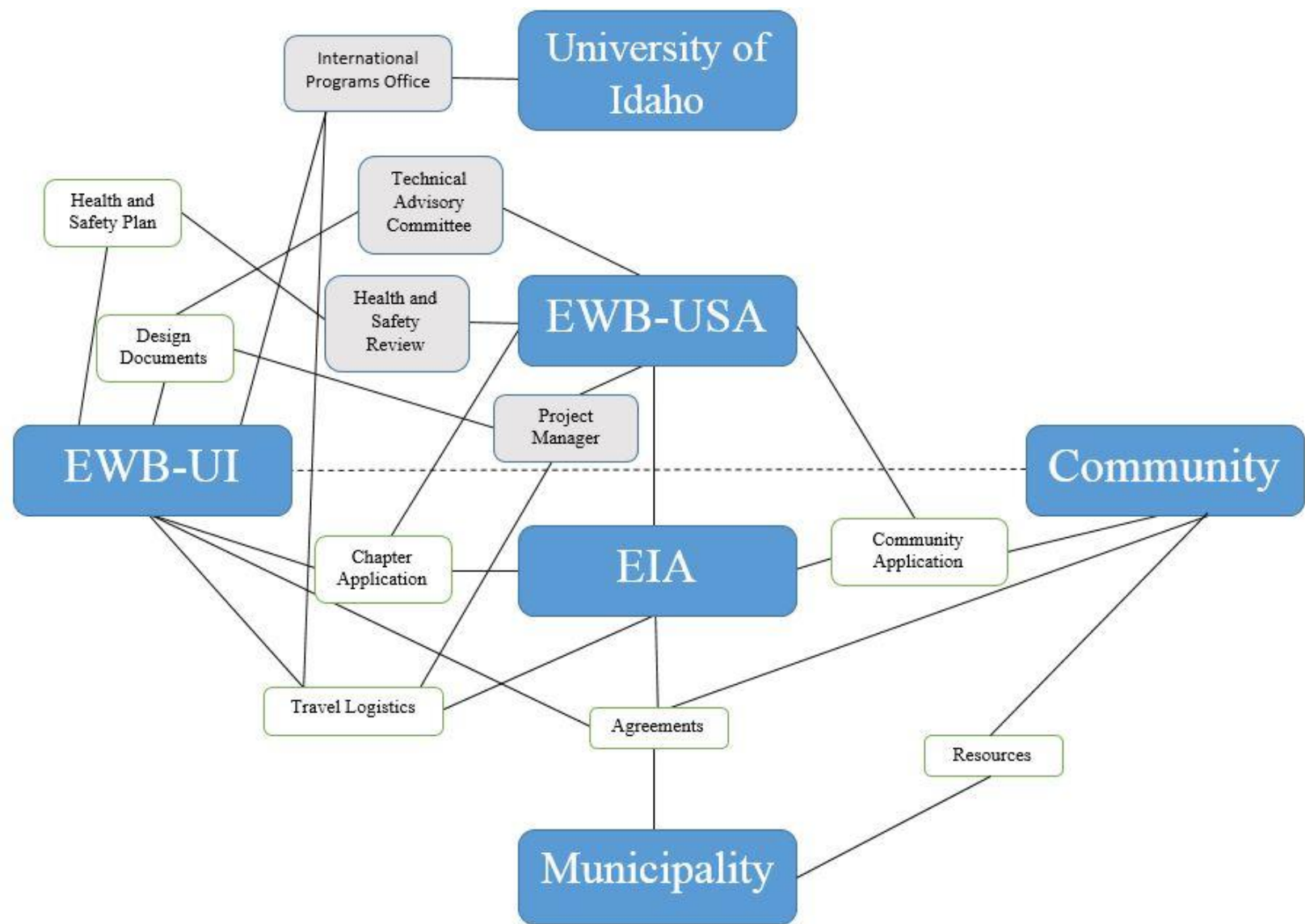

FIGURE 1

ENGINEERS WITHOUT BORDER-UNIVERSITY OF IDAHO RELATIONSHIP WEB

The formation of EWB-UI was a long process, and the first institutional hurdle was getting approval from university General Council (lawyers). It began in 2009 with the application to form a student chapter of EWB, which requires that an agreement be signed between the university and EWB-USA. While the agreement was fairly boilerplate, the review by General Council was slow, and took many attempts to get a response. This delay was over the objection that there was not an explicit clause in the agreement that allowed for the UI administration to terminate EWB-UI at any time for any reason. This process resulted in an 18month (1.5 year) delay in starting the chapter. In the end, one sentence was added to the agreement and the EWB-UI chapter was formed. 


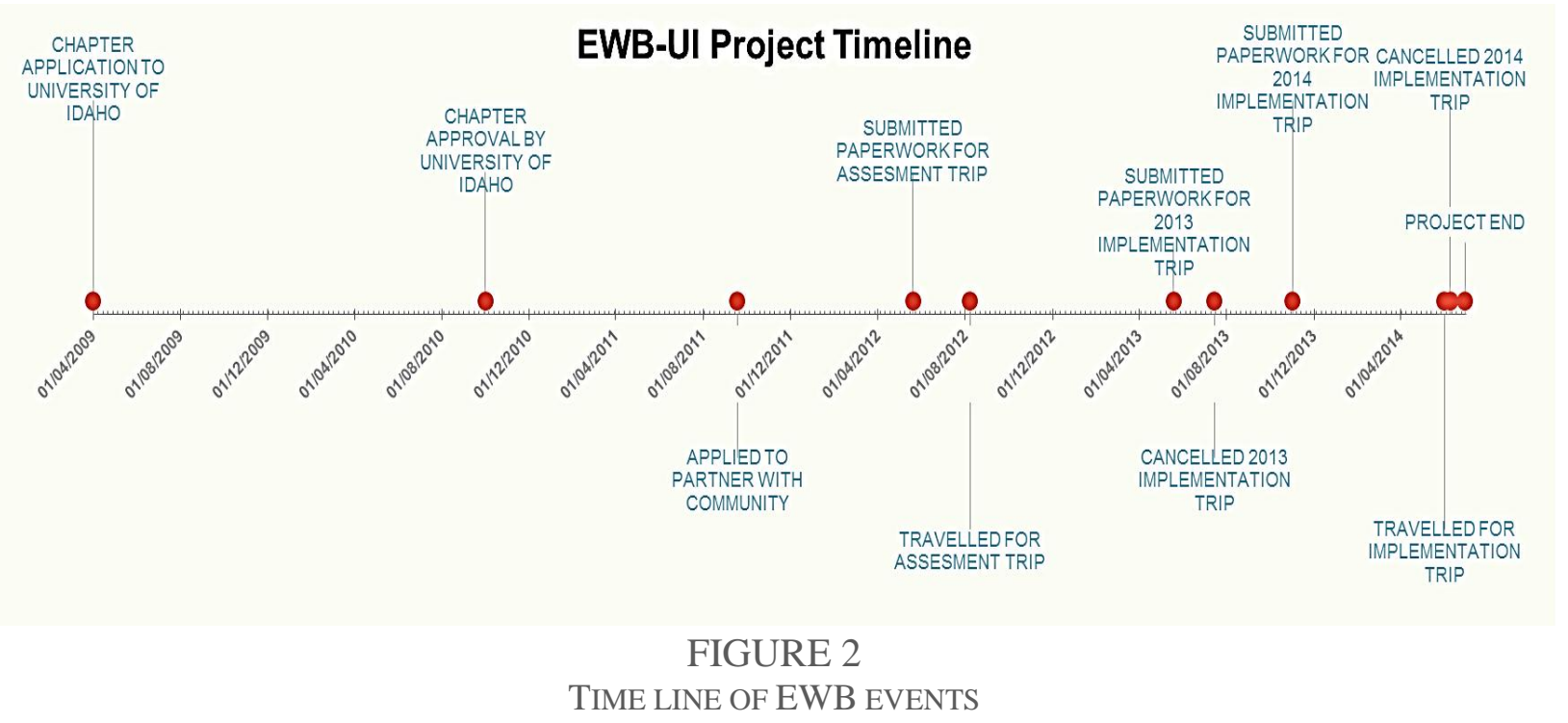

The project selection process was, and also proved to be difficult. For a newly formed chapter with no established relationships and no knowledge of the EWB-USA process, it seemed almost impossible to identify the most important community selection criteria. Imagine selecting a job that you would be working at for the next five years based on geographical location and limited amount of demographic and social information. Our group knew that our knowledge was not sufficient to make an informed decision, so with the intent of finding a better way to proceed, some of our officers and members attended an EWB conference in Louisville, KY where we were fortunate to meet a woman who worked for Engineers in Action (EIA), a Bolivian NGO. She recommended that we look at their projects in Bolivia. EWB-UI then spoke with the director of EIA, were impressed with EIA's approach to projects, and decided to choose one that was recommended to us, working with a community in the Bolivian Altiplano.

After submitting the EWB-USA paperwork to adopt the program, the team was notified of approval and began the process of preparing for an assessment trip and raising funds to travel. Luckily, the UI College of Engineering Office of Development connected us with a donor who gave a $\$ 10,000$ gift that allowed our chapter to travel the following summer. Without this, as a university in a small town, we would likely have to delay the assessment trip while our own fundraising grew and our knowledge of other funding sources increased.

Another institutional hurdle for us was interactions with the UI International Programs Office (IPO) and Risk Management. At UI, it is mandated that all student international travel be coordinated through IPO, which works with Risk Management. The university does not have a bureaucratic classification that fits EWB and classified us as a Study Abroad Program. As such, IPO initially wanted to charge each student $\$ 200$ to participate, even though we were going make all of our own travel arrangements. This is unlike students in the true Study Abroad Program, who attend foreign universities that have agreements with UI, usually for a semester or more. While we have so far managed to convince IPO to agree not to charge us this fee, it will likely come up again. More recently, UI has indicated that we must purchase travel insurance through UI, instead of an approved EWB-USA vendor. We do not know yet if the UI policy meets EWBUSA requirements, as no details have been provided. IPO is proposing that all students who 
travel internationally pay for this mandatory travel insurance in part with the fees that IPO assesses.

A 2012 assessment trip allowed the EWB-UI team to gather information needed to work with the community. We verified EIA's assessment that their priority was potable water, with irrigation as a close second, and we began to identify some possible solutions. The community was receptive and engaged. During the assessment trip, we met with the local mayor, who assured us that we had his support. After the trip, the process was facilitated by suggestions from a Bolivian engineer working for EIA, in communication with the community. The identified options were presented to the community and it was agreed that as an appropriate first step, wells would be dug similar to those in use by the community but with improved well construction and wellhead protection,

Marching forward, we submitted all of the paperwork required for implementation within the EWB-USA specified timelines. After being preliminarily approved, the team was authorized to purchase airfare tickets for the trip. In order to find the lowest cost tickets (airfare is the largest component of our budget), tickets were purchased immediately after receiving EWB-USA approval. The team continued to work through the EWB-USA approval process, getting our implementation plans approved by the Technical Advisory Committee (TAC). Review of the Health and Safety Plan (HASP) was delayed within EWB-USA because the first reviewer did not respond to our EWB-USA project manager. With the trip quickly approaching, the team continued preparing to travel. Important to note here is that grant funds obtained through EWB-USA are not released until all approvals are complete, and for implementation we needed to get funds to EIA to purchase construction materials.

Another week passed as a new reviewer was identified. Unfortunately, this reviewer appeared to struggle to understand our project, either because we were not clear or that the reviewer (who are volunteers) did not have the appropriate expertise. This was compounded by the fact that the HASP reviewer was not present for the TAC review, where design considerations are presented and discussed. The HASP review continued to be delayed. With only weeks until the travel date, the HASP reviewer stipulated that our team must have a licensed geotechnical engineer on site during construction. Our team attempted to explain the simplicity of the project, but with less than two weeks to travel and uncertainty if the materials could be purchased in time, we made the decision to postpone our implementation trip for one year. Subsequently, the president of EWB-USA stepped in to remove the HASP-reviewer stipulation to have a geotechnical engineer on site, but it was too late. We sent the engineer from EIA to the community to apologize and to explain the situation in an attempt to maintain trust. The engineer also brought a suction hose for a trash pump that had been requested by the community as a gift.

In the following year, the team made minor modifications to the design and prepared to travel. Paperwork was submitted several months ahead of the EWB deadlines to minimize the chance of additional mishaps. The trip had to be scheduled in June, instead of the ideal month of August when water levels were lowest, because the airline would only extend the rebooking of the tickets (with a fee) for one year. Just before travelling, our team was informed that we would not have the same Bolivian engineer from EIA that we, and more importantly the community, had been working with before. Unfortunately, this turned out to be an important development.

Here is where things really got interesting: upon arriving in the community, the first person that we spoke to told us that we were not welcome, that we were involved with USAID and were likely spies. After we recovered from the initial shock, we talked to other community 
members and in a few hours we were granted access to the community meeting room where we could sleep for the night with an agreement that we would have a community wide meeting in the morning. Morning came and about 20 people from the community gathered for the meeting, including their elected leader. At this meeting the community told us that they had not been notified by EIA when to expect us. While this was surprising, and not true to our actual knowledge, we apologized for the misunderstanding, which seemed to satisfy their concerns.

Then the real problem and source of their anger was raised: while travelling on behalf of our group, the engineer from EIA that we were previously working with had also been performing interviews and giving gifts on behalf of another NGO. In the community there was an orphaned boy who was thirteen at the time of the construction trip. This engineer had conducted a video interview with him and used it to raise money to give to this child. He had also arranged for a way to allow this boy to leave the community and go to an orphanage without the permission of his older brother. These actions were extremely unpopular with the community, and since "our" engineer did it, they were conflated with our activities.

After hours of explaining and apologizing, the community seemed to understand that we were not the group responsible for the situation with the orphaned boy, and they agreed to work with us. It was interesting that their elected leader was quiet and reserved, letting others "lead" the conversation. We discussed the design of the wells and found out that the community consensus had transitioned from wanting potable water to irrigation water. We set out to select several locations that would be most beneficial in hopes of finding a location that might have water quantities adequate for irrigation. Initially, the community wanted us to install clusters of wells close together in the riverbed. We explained that we were uncomfortable with installing wells in the riverbed because they would be contaminated and/or washed away. We also tried to explain that installing three wells next to each other does not produce three times the water, that the wells "steal" groundwater from each other. A community member then told our group that "your theory may be fine in the lab but out here it is garbage". This individual was the same one who accused our team of being spies, and had several times asked us how much money our group had. We then found out that he was the older brother of the orphan boy, was still upset about what had happened the previous year, and was actively trying to sabotage the project.

While this was going on, more difficulties arose with the mayor of the local municipality. The mayor had previously promised us the use of the backhoe for one week to help install the wells. At the first meeting during the construction trip the mayor first said that we would only be allowed to use it for one day. At the second meeting he said that we would be unable to use it at all. His reason was that we did not have a current signed agreement between EIA and the community. There was such a signed agreement, but it was clear that there was no room for discussion. After four days of negotiating, apologizing, and attempting to overcome the challenges, our team packed up and headed home.

\section{DISCUSSION AND RECOMMENDATIONS}

While the institutional hurdles that can arise during small-scale development work are complex and sometimes interacting, our analysis is divided into four categories by institution: UI, EWBUSA, EIA, and the local community. In this section, we examine the difficulties that arose with

each institution and offer advice to deal with these difficulties as appropriate. The goal of this 
analysis is not to disparage any organization, but rather offer areas for consideration that may allow other groups to avoid some of the difficulties experienced by our group.

At the university level, the first institutional hurdle was the initial difficulty with General Counsel while trying to get the EWB-UI chapter approved. This was a problem that could have easily ended the EWB-UI chapter before it began. With a 1.5 year delay, many of the students who were initially interested had graduated and moved on by the time the agreement was approved. In our case, even the Dean of the College of Engineering could not make progress with General Counsel. In fact, the Dean told the faculty advisor that he did not believe that EWB-UI could be having such problems until he himself tried. The problem was eventually solved by working through administrative assistants. When forming a new chapter, we recommend that students and potential faculty advisors meet with administration officials to build support beyond the department or even college level prior to submitting paperwork to start a chapter. Universities have many systems in place to capture donor dollars as well as promoting public relations and outreach for the university. These systems can be used to help connect EWB groups with donors and to help increase their potential option for publicity and outreach. An additional benefit of building administrative support early on is that it helps the chapter gain visibility, potentially leading to further opportunities for collaboration and donor support.

Working with our International Programs Office or Risk Management was also difficult. These offices exist in part to protect students and the university from liabilities associated with international travel. But bureaucratic structures can be inflexible and in our case unable to account for differences between EWB's service activities and the accredited, semester-long Study Abroad trips that involve transfer of academic credit and financial aid from one university to another. The IPO at UI does logistical planning for Study Abroad programs, most of which does not apply to EWB-UI as we perform our own planning. Fundraising is a significant challenge to EWB-UI, and having fees imposed by the university may hamper our service mission by either requiring additional fundraising, or by discouraging student participation additional burdens would fall on each student. We suggest negotiating and relying on the relationships built with administrators in other units for assistance. As well as overseeing study abroad programs the IPOs and similar departments often have the mission of promoting international education efforts on the campuses. By helping to support the IPO in these outreaches you can build allies within the office as well as promoting EWB within the university.

In working with EWB-USA there are institutional hurdles that arise from both the large number of EWB chapters and the difficulty of working with a partially volunteer workforce. EWB-USA has grown exponentially over the past decade and in trying to standardize and facilitate student humanitarian engineering work, EWB-USA has developed a series of required documents and created templates for chapters to use. The paperwork requirements can seem cumbersome, but are important because they help to regulate project quality. A large amount of paperwork is required for the travel team, with each trip requiring between 10 and 12 submissions ranging from a several pages to the 80+ page HASP. If this process could be streamlined to reduce some of the redundancy, it could reduce the paper burden and help to make the project process less daunting for new chapters. We encourage EWB student chapters to write clear, straightforward documents, limiting their length to facilitate reviews by EWB-USA. On the flip side, EWB-USA should continue to look for ways to streamline the reporting and review process, reduce redundancy, and improve feedback given to student groups. Our perception is that EWB-USA project managers have many projects to track, making it difficult for them to follow the details of any particular chapter. 
An inherent challenge facing EWB-USA is that they rely on volunteers to help with reviews. The Technical Advisory Committee (TAC) is a committee, and thus can still function when all members are not available. In comparison, the Health and Safety Plan (HASP) is reviewed by a single individual, which can become a bottleneck. In our case, this led to the cancellation of the initial EWB-UI assessment trip. The TAC and HASP reviews were completely separate, and our HASP reviewer had questions that were addressed in the TAC review. These questions took valuable time to address. EWB-USA has rectified this problem by arranging for a back-up reviewer who can expedite the process if not complete by a certain date. We suggest that EWB student chapters submit documents as early as practically possible and not assume that the deadlines specified by EWB-USA are adequate for their review. In doing so, student chapters may also realize cost savings by being approved to make travel arrangements early.

Student chapters' in-country partners provide an essential link between communities and student teams. They facilitate communication, assist with cultural differences, understand local governments, and provide logistical support. However, despite the challenges inherent to direct communication between student groups and the communities they serve, it is important that the in country partner not be the only means of contact between the team and the community. In our case, we may have discovered some issues if we had been in direct contact with the community. Communicating with community leadership is critical and allows the team to ensure that the needs, goals, and project plans are being conveyed and understood to the satisfaction of the community members. Knowing how a community's leadership changes is vital. In our case, the community leadership changed every year and we began the design with one leadership group and ended with a different group. Such leadership change contributes to a change in priorities. A Memorandum of Understanding (MOU) can help to provide clarity, by defining the overreaching goals for the whole program, to the extent that such documents have value in the community. Since projects are implemented in stages, we recommend developing a general MOU during the first trip if possible. Details should be added and modifications made to this living document as the project progresses. By being aware of the political structure of the community, and using documentation to provide continuity, it may become easier to facilitate the communication necessary for international projects.

In some areas of the world it is entirely possible that multiple humanitarian organizations may work in the same area and within a particular community. In our case, EIA was working with another NGO and EWB-UI in the same community. This caused confusion and resentment within the community when the actions done in the name of the other NGO were conflated with the work of EWB-UI. There was actually a third NGO wanting to help with water systems in the community when we were there for implementation, separate from EIA, which caused the community to be even more uncertain. While it is impossible to control other groups, in talking directly with the community, student humanitarian groups would be wise to clearly identify other organizations working with them and either avoid conflicts or create synergies. In the case of the EWB-UI trip the travel team was aware of other NGO's that had operated in the country prior to the EWB project but were unaware that an additional NGO had begun working in the community.

The trouble that arose with the local government was difficult to anticipate. During the assessment trip the mayor thanked us for coming and ensured our team that he would provide support for this project. EIA provided us with information on the agreements that were needed between EWB-UI, EIA and the local government, which were completed and presented to the 
mayor by EIA. EWB-UI also wrote the mayor a letter prior to our trip, stating our intentions and needs. However, upon arriving for implementation, the municipal government seemed much less willing to cooperate, initially telling us that they did not have the document needed for the agreement. After being allowed to examine the records ourselves, our team was able to show that we did in fact submit the document. We were then told that it was out of date and would not be honored. We do not know the source of the mayor's sudden reluctance to partner with us. Our recommendation moving forward is to bring copies of any agreements made between parties and to ask what the life of these documents is at the time that you are establishing these agreements. Find out if the document you are working with has an expiration period and will need to be renewed periodically or if it is simply a one-time formality.

\section{CONCLUSION}

The goal of this paper is to present a case study to examine some of the institutional hurdles that can hinder the progress of student humanitarian groups. While working through various institutions can be a complex and difficult endeavor, it is important to remember that these institutions enable humanitarian projects to occur. Without them, there would be far fewer deserving people being helped and fewer students participating in these broadening experiences. Both EWB-USA and EIA were extremely responsive in dealing with the situations described, and immediately implemented policy changes. Our intent is to help others navigate this complex landscape.

The scope of the organizations that a volunteer group will work with range greatly - from small NGOs with few administrative hurdles to large complex institutions with many layers of administration. In both of these extremes, it is important to establish contact with individuals within the organization that are reliable and can aid the group in navigating some of the challenges that may occur. In larger organizations, such as universities, it is necessary to establish multiple such contacts in various units. These individuals can champion the project throughout their organization and can help to navigate hurdles that will undoubtedly arise.

Finally, the difficulties that we encountered while working with various institutions highlight the importance of timely, accurate, and complete communication. Student humanitarian engineering groups should never assume that the information given to them is complete, or that communications made through another party accurately reach their intended audience. It is important to ask questions to verify understanding and to extract information. We suggest that student groups attempt to inform communities about the EWB (or other) process, so that communities fully understand that projects take time, that delays beyond the control of the group are possible, and that neither of these will affect the commitment of the student group to the community. Long and unexpected delays can easily erode the trust of the community. Even with the best efforts and intentions, student groups should understand that failure is likely, and instead of being discouraged, should attempt to learn from mistakes and move forward with their mission. Failure offers incredible opportunities for growth, as individuals and as organizations. By studying and learning from the lessons presented from the described failures it is possible to provide a source of knowledge that can be utilized by organizations at many different stages in the project process. This knowledge may help organizations avoid pitfalls and help to improve the success rates of these small-scale humanitarian engineering projects. 


\section{ACKNOWLEDGEMENTS}

The authors would like to acknowledge Ricardo Condori for his tireless efforts while working in the community. We would also like to thank Cathy Leslie from Engineers Without Borders USA, and David Stephenson from Engineers In Action for their help during the comment process. I would also like to acknowledge the members of EWB-UI for all of the hard work that they have done. Finally, I would like to thank Fritz Fiedler for his support and advice throughout the project and the paper process.

\section{REFERENCES}

1 "MIT Courses." D-Lab. April 14, 2014. Accessed August 20, 2014.

2 "The Humanitarian Engineering Program." Colorado School of Mines HE Program. August 4, 2014. Accessed August 20, 2014.

3 "Humanitarian Engineering Scholars." Honors Scholars. January 1, 2013. Accessed August 20, 2014.

4 "University of Dayton, Ohio." ETHOS:. January 1, 2014. Accessed August 20, 2014.

5 "Impact Analysis." Dartmouth Humanitarian Engineering. January 1, 2012. Accessed August 20, 2014.

${ }^{6}$ Amadei, Bernard, Robyn Sandekian, and Evan Thomas. "A Model for Sustainable Humanitarian Engineering Projects." Sustainability, 2009, 1087-105. November 20, 2009. Accessed August 1, 2014.

${ }^{7}$ Dukhan, N., M.R. Schumak, and J.J. Daniels. "Implementation of Service-learning in Engineering and Its Impact on Students' Attitudes and Identity." European Journal of Engineering Education 33, no. 1 (2008): 21-31.

${ }^{8}$ Amadei, Bernard. "Development Project Frameworks." In Engineering for Sustainable Human Development. Reston: American Society of Civil Engineers, 2014.

9 "Reading Room." Admitting Failure. January 1, 2014. Accessed August 25, 2014.

10 "Fail Forward for Nonprofits." Fail Forward RSS. January 1, 2014. Accessed August 27, 2014.

${ }^{11}$ Mazzurco, Andrea, and Brent K. Jesiek. "Learning from Failure: Developing a Typology to Enhance Global Service-learning Engineering Projects." American Society for Engineering Education, 2014. 